\title{
Co-existence of beta-lactamases in clinical isolates of Escherichia coli from Kathmandu, Nepal
}

\author{
Ram Hari Pokhrel', Badri Thapa ${ }^{2,3^{*}}$, Rajesh Kafle ${ }^{1}$, Pradeep Kumar Shah ${ }^{1}$ and Chanwit Tribuddharat ${ }^{4}$
}

\begin{abstract}
Background: The trend of extended-spectrum beta-lactamases producing Escherichia coli (ESBL-EC) is increasing in Nepal. Limited studies have been reported investigating ESBL types and carbapenemases in E. coli.

Methods: A cross sectional study was conducted between June 2012 to January 2013 in Kathmandu Medical College and Teaching Hospital, Nepal. Non-repetitive clinical samples from out-patient department (OPD) and Intensive Care Units (ICU) were processed for bacteriological culture and identification of E. coli. Antibiotic susceptibility test, screening and phenotypic confirmation for ESBLs and carbapenemases and PCR (b/a $a_{\mathrm{CTX}-\mathrm{M}}$, bla $a_{\mathrm{SHV}}$ and bla $a_{\mathrm{TEM}}$-type ESBLs, blaviM, bla $a_{\text {IMP }}$ and bla $a_{\text {NDM-1 }}$-type carbapenemases, and class 1 integron element integrase gene) were performed. Clones were resolved by PCR-Randomly Amplified Polymorphic DNA.
\end{abstract}

Results: Out of 332 non-repetitive clinical specimens processed for culture and identification 160 (48.2\%) were culture positive. Of which, 93 (58.1\%) were E. coli. Of these, 24 (25.8\%) were phenotypically confirmed as ESBL-EC and 3 (12.50\%) of 24 ESBL-EC were carbapenemase producers. bla $a_{C T X-M}$-type ESBL was most common $(23,95.8 \%)$ followed by bla $a_{T E M}(7,29.2 \%)$ and bla $a_{\mathrm{SHV}}(3,12.5 \%)$. bla $\mathrm{V}_{\mathrm{VIM}}$, bla $a_{\mathrm{IMP}}$ and bla $\mathrm{ADMM}_{\mathrm{I}-1}$ were present in 3,2 and 2 ESBL-EC, respectively. Class 1 integron element was present in 18 (75.0\%) ESBL-EC. Nine isolates possessed more than one type of beta-lactamases. Interestingly, all carbapenemase producers were isolated form ICU and co-existence of bla $a_{\mathrm{CTX}-\mathrm{M}}, b / a_{\mathrm{SHV}}, b a_{\mathrm{TEM}}$, bla $a_{\mathrm{MP}}$, bla $a_{\mathrm{VIM}}$ and bla $a_{\mathrm{NDM}-1}$ beta-lactamases was documented in one ESBL-EC (EC104). All most all isolates had different RAPD patterns.

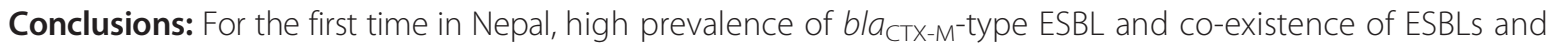
carbapenemases has been described. Continuous monitoring and surveillance and proper infection control and prevention practices will limit the further spread of these super-bugs within this hospital and beyond.

Keywords: ESBL producing Escherichia coli, Carbapenemases, Clinical isolates, Integron element

\section{Background}

Escherichia coli is associated with numerous infections such as urinary tract infection, surgical site infection, skin and soft tissues infection, bacteraemia, pneumonia etc [1-3]. These infections are common among outpatient and Intensive Care Unit (ICU) admitted patients [4]. ICU patients are subjected to numerous invasive procedures and are susceptible to ICU acquired infections (IAI) and Escherichia coli is a common pathogen [5]. Extended-spectrum beta-lactam antibiotics-third generation cephalosporins- are commonly used for treating

\footnotetext{
* Correspondence: badri_bishal@yahoo.com

${ }^{2}$ Department of Microbiology, Kathmandu Medical College and Teaching Hospital, Kathmandu, Nepal

${ }^{3}$ Genesis Laboratory and Research, Kathmandu, Nepal

Full list of author information is available at the end of the article
}

infections caused by Escherichia coli in Kathmandu Medical College and Teaching Hospital (KMCTH), Nepal. These antibiotics are less effective as Extended-spectrum beta-lactamase producing isolates of E. coli (ESBL-EC) is increasing in this institution [6]. Carbapenems are current choice for treating the infection caused by ESBL-EC however, emergence of carbapenem-resistant isolates has also been noticed [7]. Hence, the successful treatment outcome of $E$. coli infections is seriously tempered by these ESBLand carbapenem-resistance.

Increase trends of ESBL and carbapenem-resistance over the past two decades has been noticed globally and also in Nepal $[6,8,9]$. Several variants of ESBLs; TEM, SHV and CTX-M have been described however; there is paucity in studies of ESBL and carbapenemases types 
from this institution and Nepal. This study aims to detect common ESBLs (bla $a_{\mathrm{TEM}}, b l a_{\mathrm{SHV}}$, and $b l a_{\mathrm{CTX}-\mathrm{M}}$ ) and carbapenemases $\left(b l a_{\mathrm{IMP}}, b l a_{\mathrm{VIM}}\right.$, and $\left.b l a_{\mathrm{NDM}}\right)$ in ESBL-EC isolated from Kathmandu Medical College Teaching Hospital, Nepal. Here, we describe high prevalence of bla $a_{\mathrm{CTX}-\mathrm{M}}$ type ESBL and carbapenemases producing E. coli and co-existence of ESBLs and carbapenemases in these isolates.

\section{Methods}

\section{Specimens, inclusion criteria and identification of $E$. coli} isolates

Non-repetitive clinical specimens (mid-stream urine, pus, discharge from surgical wound, endotracheal secretions, sputum, catheter tips etc.) received as part of standard patient care investigation from Intensive Care Unit (ICU) and out-patient department (OPD) in Kathmandu Medical College and Teaching Hospital between June 2012 to January 2013 were processed for culture and antibiotic susceptibility testing from patients attending OPD and admitted in ICU were included in the study. The patients already on antibiotics were excluded based on the history of antibiotics mentioned in the culture investigation form. E. coli isolates were isolated and identified using standard microbiological technique [5].

\section{Identification of $E$. coli isolates}

All specimens were cultured on MacConkey and blood agar and incubated overnight at $37^{\circ} \mathrm{C}$ in the department of microbiology, KMCTH using standard microbiological technique [10]. On grown lactose fermenting colonies biochemical tests was performed to identify E. coli.

\section{Anti-microbial susceptibility technique}

Kirby-Bauer disk diffusion test was performed on identified E. coli on Mueller-Hinton agar according to Clinical and Laboratory Standards Institute guidelines (CLSI) [11]. The following antibiotic disks procured from Hi Media Pvt. Ltd., India were used; ampicillin $(20 \mu \mathrm{g})$ nalidixic acid $(30 \mu \mathrm{g})$, amoxycillin $(30 \mu \mathrm{g})$, amoxycillin-clavulinic acid $(30 \mu \mathrm{g} / 10 \mu \mathrm{g})$, cefepime $(30 \mu \mathrm{g})$, cefotaxime $(30 \mu \mathrm{g})$, ceftriaxone $(30 \mu \mathrm{g})$ and ceftazidime $(30 \mu \mathrm{g})$, amikacin $(30 \mu \mathrm{g})$, tobramycin $(30 \mu \mathrm{g})$, gentamycin $(10 \mu \mathrm{g})$ and imipenem $(10 \mu g)$.

\section{Screening and phenotypic confirmation of ESBL and carbapenemase producers}

The screening for ESBLs producers were performed using cefotaxime $(30 \mu \mathrm{g})$, ceftazidime $(30 \mu \mathrm{g})$ and ceftriaxone $(30 \mu \mathrm{g})$ and interpreted based on CLSI guidelines [11]. Phenotypic confirmation of ESBL producers were confirmed using ceftazidime disc $(30 \mu \mathrm{g})$ alone and in combination with clavulanic acid $(10 \mu \mathrm{g})$. Similarly, imipenem resistant $E$. coli were confirmed for carbapenemase production by modified Hodge test [11].

\section{Genotype confirmation of ESBLs and carbapenemases}

Crude DNA was extracted from pure culture of $E$. coli. Briefly, fresh culture of the test organism was suspended in $500 \mu \mathrm{l}$ of saline, vortexed, boiled for 10 minutes, cellular debris was removed by centrifugation at 11,000 rpm for 5 min and supernatant was used as DNA template for PCR analysis. PCR amplification of the drug resistance genes like $b l a_{\mathrm{TEM}}, b l a_{\mathrm{SHV}}, b l a_{\mathrm{CTX}-\mathrm{M}}, b l a_{\mathrm{IMP}}, b l a_{\mathrm{VIM}}$ and $b l a_{\mathrm{NDM}-1}$ was performed using gene specific primers (Table 1) and amplification profiles described earlier [12-14]. The PCR was performed in Genesis Laboratory and Research, Kathmandu, Nepal.

\section{Controls}

ESBL negative E. coli (ATCC 25922), ESBL positive $K$. pneumoniae (ATCC 700603) and Imipenemase producing Pseudomonas aeruginosa were used as controls in disk diffusion test, screening and confirmation tests. Multiple strains of $P$. aeruginosa genetically characterized to produce TEM, CTX-M, SHV, IMP, VIM and NDM-1 were used as positive controls for PCR.

\section{Clonal analysis}

Polymerase Chain Reaction-Randomly Amplified Polymorphic DNA (PCR-RAPD) was to study the clonal nature of these isolates as described previously [13].

\section{Data analysis and ethical approval}

The data is presented in frequency and percentages. The study was approved by the Institutional Ethical

\section{Table 1 Primers used in this study}

\begin{tabular}{|c|c|c|c|}
\hline $\begin{array}{l}\text { Name of } \\
\text { the primer }\end{array}$ & Target & Amplicon (bp) & Sequence $5^{\prime}-3^{\prime}$ \\
\hline TEM1F & \multirow{2}{*}{$b l a$ TEM } & \multirow{2}{*}{864} & ATGAGTATTCAACATTTCCG \\
\hline TEM1R & & & CTGACAGTTACCAATGCTTA \\
\hline SHVF & \multirow{2}{*}{$b^{\prime} a_{\mathrm{SHV}}$} & \multirow{2}{*}{865} & GGTTATGCGTTATATTCGCC \\
\hline SHVR & & & TTAGCGTTGCCAGTGCTC \\
\hline CTX-MA1 & \multirow{2}{*}{ blactX-м } & \multirow{2}{*}{544} & ${ }^{*}$ SCSATGTGCAG ${ }^{*}$ YACCAGTAA \\
\hline CTX-MA2 & & & CCGC ${ }^{*}$ RATATGRTTGGTGGTG \\
\hline IMP F & \multirow{2}{*}{$b / a_{\mathrm{IMP}}$} & \multirow{2}{*}{569} & TTGCCAGATTTAAAAAT \\
\hline IMP 003 & & & ACCAGTITGCCTTACCATA \\
\hline VIM F & \multirow{2}{*}{ bla $_{\mathrm{VIM}}$} & \multirow{2}{*}{551} & GTCTACCCGTCCAATGGTCTCA \\
\hline VIM R & & & AGCAAGTCTAGACCGCCCG \\
\hline NDM-1 F & \multirow{2}{*}{$b^{b} a_{N D M-1}$} & \multirow{2}{*}{593} & GGTTTGGCGATCTGGTTTC \\
\hline$N D M-1 R$ & & & CGGAATGGCTCATCACGATC \\
\hline Intl1F & \multirow{2}{*}{ intl1 } & \multirow{2}{*}{471} & AAGGATCGGGCCTTGATGTT \\
\hline Int11R & & & CAGCGCATCAAGCGGTGAGC \\
\hline
\end{tabular}

Note: ${ }^{*} \mathrm{~S}=\mathrm{G}$ or $\mathrm{C},{ }^{\neq} \mathrm{Y}=\mathrm{C}$ or $\mathrm{T},{ }^{¥} \mathrm{R}=\mathrm{A}$ or $\mathrm{T}$. 
Table 2 Distribution of ESBL, carbapenemase and Int/1 in ESBL producing E. coli

\begin{tabular}{|c|c|c|c|c|c|c|c|}
\hline ESBL producing $E$. coli & $b l a_{\text {CTX-M }}$ & $b l a_{\mathrm{SHV}}$ & $b l a_{\mathrm{TEM}}$ & $b l a_{\mathrm{NDM}-1}$ & $b l a_{1 \mathrm{MP}}$ & $b l a_{\mathrm{VIM}}$ & Intl 1 \\
\hline EC17, $-23,-42,-103,-105,-106,-108,-205,-208,-209$ & + & - & - & - & - & - & + \\
\hline EC206, $-207,-210,-211$ & + & - & - & - & - & - & - \\
\hline EC98, -102 & + & + & - & - & - & - & + \\
\hline EC202, -204 & + & - & + & - & - & - & + \\
\hline EC203, -212 & + & - & + & - & - & - & - \\
\hline EC100 & + & - & + & + & - & + & + \\
\hline EC104 & + & + & + & + & + & + & + \\
\hline EC107 & + & - & + & - & + & + & + \\
\hline EC201 & - & - & - & - & - & - & + \\
\hline
\end{tabular}

Review Board of Kathmandu Medical College and Teaching Hospital, Kathmandu, Nepal.

\section{Results}

During the study period, 332 non-repetitive clinical samples $[n=292($ OPD) and $n=40($ ICU) $]$ were processed and 160 samples (48.2\%) $[\mathrm{n}=130(\mathrm{OPD})$ and $\mathrm{n}=30$ (ICU)] were culture positive. These specimens were received from urinary tract infections $(110,68.8 \%)$, respiratory tract infections $(19,11.9 \%)$, surgical site infection $(16,10.0 \%)$, skin and soft tissue infection $(12,7.5 \%)$ and blood stream infection $(3,1.9 \%)$ and $E$. coli was predominant pathogen $(93,58.1 \%)$. E. coli were derived mostly from urinary tract infection $(80,86.0 \%)$. Of which, 24 (25.8\%) were phenotypically confirmed as ESBL-EC among which 10 ESBL producing isolates were from ICU. All ESBL-EC were found to be resistant to nalidixic acid, amoxycillin, cefepime, cefotaxime, ceftriaxone and ceftazidime. ESBL-EC were also resistant to amoxicillin-clavulinic acid $(23,95.8 \%)$, cotrimoxazole $(21,87.5 \%)$, imipenem $(3,12.5 \%)$, gentamicin $(2,8.3 \%)$, amikacin $(1,4.2 \%)$ and tobramycin $(1,4.2 \%)$.

bla $a_{\mathrm{CTX}-\mathrm{M}}$ was the most prevalent ESBLs $(23,95.8 \%)$ followed by $\operatorname{bla}_{\mathrm{TEM}}(7,29.2 \%)$ and bla $a_{\mathrm{SHV}}(3,12.5 \%)$ (Table 2). Among ESBL-EC, 3 (12.5\%) (EC100, EC104 and EC107) isolates were screened and confirmed as cabapenemase producers. All these 3 isolates were from ICU. bla $a_{\mathrm{VIM}}$ was present in all of these isolates, $b l a_{\mathrm{NDM}-1}$ was present in 2 isolates (EC100 and EC104) and bla $a_{\mathrm{IMP}}$ was present in 2 isolates (EC104 and EC 107). Strikingly, carbapenemase harboring isolates were found to contain more than one resistant gene under the study. Coexistence of ESBLs and carbapenemases among ESBL-EC was variable (Table 2). An EC104 harboured all resistant genes investigated. Class 1 integron element was prevalent among the ESBL producers $(18,75.0 \%)$.

All isolates of $E$. coli were subjected for RAPD. The isolates showed different RAPD patterns. Isolates EC106 \& EC107 possessed similar RAPD patterns and rest of the isolates had individual RAPD patters (Figure 1).

\section{Discussion}

E. coli is responsible for numerous infections and is frequently involved in sepsis and other infections in OPD and critically ill patients in Intensive Care Units (ICU) $[5,15]$. The emergence of ESBL producing E. coli (ESBL$\mathrm{EC}$ ) is a real challenge for infectious disease medicine as these bugs are increasingly detected worldwide particularly in ICU $[15,16]$. ESBL-EC infections ultimately results in unavoidable treatment outcomes and increases

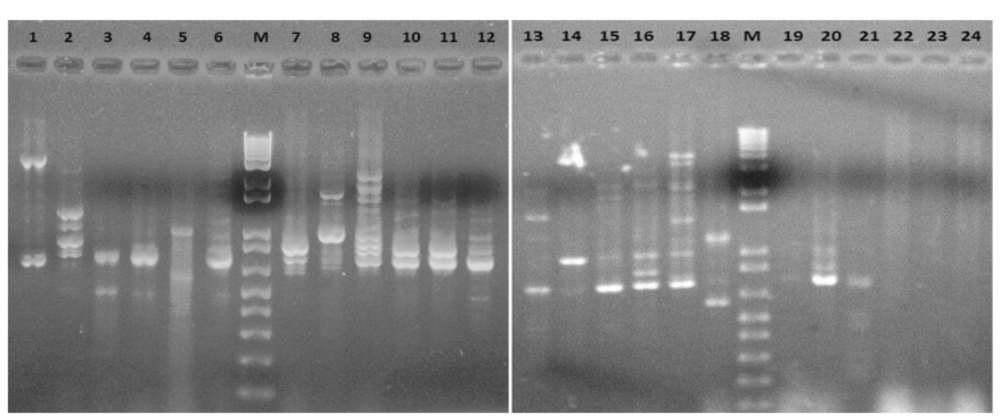

Figure 1 Gel electrophoresis of PCR amplicons of RAPD patterns. Lane M: Molecular weight marker (1 kb+ Invitrogen). Lane 1-24: E.coli isolates, EC17, EC23, EC42, EC98, EC100, EC102, EC103, EC104, EC105, EC106, EC107, EC108, EC201, EC202, EC203, EC204, EC205, EC206, EC207, EC208, EC209, EC210, EC211 and EC212. 
the cost in patients. In this study, 58.1\% (93/160) of the infections were caused by $E$. coli. Of these infections, $25.8 \%(24 / 93)$ and $3.2 \%(3 / 93)$ were caused by ESBLEC and carbapenemase producing $E$. coli, respectively. Frequency of isolation of $E$. coli is also common in ICUs elsewhere however infections due to ESBL-EC and carbapenemase producer vary among different geographical regions [5,17]. Since 2000, the already ubiquitous $E$. coli has emerged as major ESBL producing organism. In 2007 , already $79 \%$ of $E$. coli isolates collected in India were positive for ESBLs, with almost identical prevalence in hospital and community [18], $55 \%$ in China and 50.8\% in Thailand [17]. ESBL-EC in ICU are increasing than general wards and out patients in this institution which is worrisome [6].

We have detected a variety of beta-lactamases among the isolates of $E$. coli namely $b l a_{\mathrm{CTX}-\mathrm{M}}, b l a_{\mathrm{TEM}}, b l a_{\mathrm{SHV}^{-}}$ type enzymes. The $b l a_{\text {СтX-M }}$ type was the most prevalent ESBL $(\mathrm{n}=23)$. The incidence of this enzyme surpasses those of $b l a_{\mathrm{TEM}}$ and $b l a_{\mathrm{SHV}}$-type ESBLs in most locales worldwide [19] and also in our study. The wider spread of bla СтX-M is also due to over use of third generation cephalosporins which has selected these strain. Some of the $b l a_{\mathrm{CTX}-\mathrm{M}}$ types are also associated with mobile genetic elements like class 1 integron element which contributes to its wider spread [20]. This was also evident in this study as 18 out of $23 b l a_{\text {CTX-M }}$ positive isolates possessed class 1 integron element. However, the location of $b l a_{\text {СтX-M }}$ in class 1 element was not studied and needs further investigation. One of the isolate was ESBL-EC on screening and phenotypic test but didn't possessed CTX-M, TEM and SHV enzymes, other ESBLs (AmpC) or other mechanisms could be possible [21].

The prevalence of $b l a_{\mathrm{CTX}-\mathrm{M}}, b l a_{\mathrm{TEM}}$ and $b l a_{\mathrm{SHV}^{-}}$type ESBLs in $E$. coli is variable across different cities, countries and regions [22]. The prevalence of $b l a_{\text {СтX-M }}$ and $b l a_{\text {SHV }}$ genes was reported as $83 \%$ and $28 \%$, respectively in ESBL-EC in New York [23] and 22.7\% and 9.1\%, respectively in ESBL-EC in Turkey [24]. Similarly, prevalence of $b l a_{\text {СTX-M }}$ and $b l a_{\mathrm{TEM}}$ was $11 \%$ and $50 \%$, respectively in Pakistan [25]. However, the bla ${ }_{\text {СтХ-M }}$ has displaced other ESBLs in this geographical location as demonstrated in this study and also in Eastern Europe, South America, Japan and India [26].

The important finding in the study was the coexistence of different ESBLs and carbapenemases in the same isolate. Of 24. ESBL-EC, 9 (37.5\%) possessed more than one ESBLs. Study in Taiwan reported co-existence of two or more kinds of ESBL in 40.6\% of ESBL-EC [27]. Similarly, co-existence of $b l a_{\text {СTX-M }}$ and $b l a_{\mathrm{TEM}}$ was found in 52.6\% of French ESBL-EC [28]. Co-existence of NDM-1 and OXA-76 has been described in Klebsiella pneumoniae isolates from Nepal [29]. Carbapenemase producers were found to harbor carbapenemases co- existing with ESBLs. Each of EC104, EC100 and EC107 possessed $\quad b l a_{\mathrm{CTX}-\mathrm{M}}+b l a_{\mathrm{TEM}}+b l a \mathrm{SHV}+b l a \mathrm{NDM}-1+$ $b l a_{\mathrm{IMP}}+b l a_{\mathrm{VIM}}, \quad b l a_{\mathrm{CTX}-\mathrm{M}}+b l a_{\mathrm{SHV}}+b l a_{\mathrm{NDM}-1}+b l a_{\mathrm{VIM}}$ and $b l a_{\mathrm{CTX}-\mathrm{M}}+b l a_{\mathrm{TEM}}+b l a_{\mathrm{IMP}}+b l a_{\mathrm{VIM}}$, respectively. This co-existence of 6 beta-lactamases in EC104 was confirmed by multiple amplifications which is unique ESBL-EC in Nepal and elsewhere. The presence of carbapenemases like; $b l a_{\mathrm{NDM}-1}, b l a_{\mathrm{IMP}}$ and $b l a_{\mathrm{VIM}}$ and its co-existence with ESBLs like, $b l a_{\mathrm{CTX}-\mathrm{M}}, b l a_{\mathrm{TEM}}$ and $b l a_{\mathrm{SHV}}$ in $E$. coli will seriously limit present and future therapeutic options.

The study of variants of ESBL-types, their location in mobile genetic elements (plasmids and integron elements), and clonal analysis of ESBL-EC is required. PCR-RAPD is simple, easy, cost-effective and has short turn-around time to answer the clonal nature of the bacterial isolates. PCR-RAPD was performed to study the clonal nature of these isolates but none of the isolates possessing similar resistance genes were grouped into similar RAPD types. More robust tools like pulse field gel electrophoresis and multi-locus sequence typing would help to know the exact clonal nature of these isolates.

\section{Conclusion}

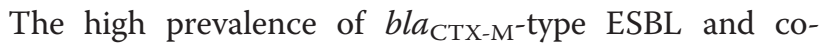
existence of ESBLs and carbapenemases were noted in ESBL-EC isolated from Kathmandu Medical College and Teaching Hospital OPD and ICU patients for the first time. Continuous monitoring of this ESBL-EC with nationwide study will shed light in its dissemination and strategy to prevent and control the further spread of these super-bugs.

\section{Competing interests}

The authors declare that they have no competing interests.

\section{Authors' contributions}

RHP collected the samples, conducted the laboratory analysis, analysed the data, and drafted the manuscript; BT designed the study, analysed the data and reviewed the manuscript; RK, PKS and CT were involved in the concept, design and review of the manuscript. All authors read and approved the final manuscript.

\section{Acknowledgements}

I would like thank Dr. Chanwit Tribuddharat for being so generous to supply the valuable reagents and control for the study and to Ms. Chandrika Devi Shrestha who helped by providing the specimens for our study. I am also grateful to the Department of Microbiology, St. Xavier's College, Nepal.

\section{Author details}

${ }^{1}$ Department of Microbiology, St. Xavier's College, Kathmandu, Nepal. 2Department of Microbiology, Kathmandu Medical College and Teaching Hospital, Kathmandu, Nepal. ${ }^{3}$ Genesis Laboratory and Research, Kathmandu, Nepal. ${ }^{4}$ Department of Microbiology, Siriraj Hospital, Mahidol University, Bangkok, Thailand.

Received: 20 May 2014 Accepted: 2 October 2014

Published: 7 October 2014 


\section{References}

1. Jacobsen SM, Stickler DJ, Mobley HLT, Shirtliff ME: Complicated catheterassociated urinary tract infections due to Escherichia coli and Proteus mirabilis. Clin Microbiol Rev 2008, 21(1):26-59.

2. Shahane V, Bhawal S, Lele U: Surgical site infections: a one year prospective study in a tertiary care centre. Int J Health Sci 2012, 6(1):79-84.

3. Wang JY, Hsueh PR, Wang JT, Lee LN, Yang PC, Luh KT: Recurrent infections and chronic colonization by an Escherichia coli clone in the respiratory tract of a patient with severe cystic bronchiectasis. J Clin Microbiol 2000, 38(7):2766-2767.

4. Guggenbichler JP, Assadian O, Boeswald M, Kramer A: Incidence and clinical implication of nosocomial infections associated with implantable biomaterials-catheters, ventilator-associated pneumonia, urinary tract infections. GMS Krankenhhyg Interdis Zip 2011, 6(1):Doc 18.

5. Meybeck A, Ricard JD, Barnaud G, Eveillard M, Chevrel G, Mounier R, Dreyfuss D: Incidence and impact on clinical outcome of infections with piperacillin/tazobactam resistant Escherichia coli in ICU: a retrospective study. BMC Infect Dis 2008, 8:67.

6. Chander A, Shrestha CD: Prevalence of extended spectrum beta lactamase producing Escherichia coli and Klebsiella pneumoniae urinary isolates in a tertiary care hospital in Kathmandu, Nepal. BMC Res Notes 2013, 6:487.

7. Rawat $D$, Nair $D$ : Extended-spectrum beta-lactamases in gram negative bacteria. J Glob Infect Dis 2010, 2(3):263-274.

8. $\quad$ Pitout JD, Laupland KB: Extended-spectrum $\beta$-lactamase-producing Enterobacteriaceae: an emerging public-health concern. Lancet Infect Dis 2008, 8(3):159-166.

9. Hammar DA, Dangol S, Anderson TP, Wong JSJ, Werno AM, Murdoch DR: High prevalence of extended-spectrum beta-lactamase-producing Enterobacteriaceae in Nepal. Int J Antimicrob Agents 2007, 30(5):471-472

10. Collee JG, Miles RS, Watt B: Tests for identification of bacteria. In Mackie and McCartney Practical Medical Microbiology. 14th edition. Edited by Collee JG, Fraser AG, Marmion BP, Simmons A. New York: Churchill Livingstone; 1996:131-149.

11. Clinical Laboratory Standards Institute: Performance Standards for Antimicrobial Susceptibility Testing; Twenty First Informational Supplement (M 100-S21). Wayne PA: Clinical and Laboratory Standards Institute; 2011.

12. Pongpech $P$, Naenna P, Taipobsakul Y, Tribuddharat C, Srifuengfung S: Prevalence of extended-spectrum beta-lactamase and class 1 integron integrase gene int/1 in Escherichia coli from Thai patients and healthy adults. Southeast Asian J Trop Med Public Health 2008, 39(3):425-433.

13. Thapa B, Tribuddharat C, Srifuengfung S, Dhiraputra C: High prevalence of bla (OXA)-23 in oligoclonal carbapenem-resistant Acinetobacter baumannii from Siriraj Hospital, Mahidol University, Bangkok, Thailand. Southeast Asian J Trop Med Public Health 2010, 41(3):625-635.

14. Nordmann P, Poirel L, Carrër A, Toleman MA, Walsh TR: How to detect the NDM-1 producers. J Clin Microbiol 2011, 49(2):718-721.

15. Brusselaers $\mathrm{N}$, Vogelaers $\mathrm{D}$, Blot $\mathrm{S}$ : The rising problem of antimicrobial resistance in the intensive care unit. Ann Intensive Care 2011, 1:47.

16. Dhillon RHP, Clark J: ESBLs: a clear and present danger. Crit Care Res Prac 2012, 2012:625170.

17. Hawser SP, Bouchillon SK, Hoban DJ, Badal RE, Hsueh PR, Paterson DL: Emergence of high levels of extended-spectrum-lactamase-producing gram-negative bacilli in the Asia-Pacific Region: data from the study for monitoring antimicrobial resistance trends (SMART) program, 2007. Antimicrob Agents Chemother 2009, 53(8):3280-3284.

18. Jahan DD, Pitout JD: Infections with extended-spectrum $\beta$-lactamaseproducing Enterobacteriaceae. Drugs 2010, 70(3):313-333.

19. Jorgensen JH, Mc Elmeel ML, Fulcher LC, Zimmer BL: Detection of CTX-Mtype extended spectrum beta-lactamase (ESBLs) by testing with microscan overnight and ESBL confirmation panels. J Clin Microbial 2010, 48(1):120-123

20. Chowdhury PR, Ingold A, Vanegas N, Martinez E, Merlino J, Merkier AK, Castro M, Rocha G, Borthagaray G, Centron D, Toledo HB, Morquez CM, Stokes HW: Dissemination of multiple drug resistance genes by class 1 integrons in Klebsiella pneumonia isolates from four countries: a comparative study. Antimicrob Agents Chemother 2011, 55(7):3140-3149.

21. Doddaiah V, Anjaneya D: Prevalence of ESBL, AmpC and carbapenemase among Gram negative bacilli isolated from clinical specimens. Am J Life Sci 2014, 2(2):76-81.
22. Al-Jasser AM: Extended-spectrum B-Lactamases (ESBLs): a global problem. Kuwait Med J 2006, 38(3):171-185.

23. Jones TH, Tuckman M, Keeney D, Ruzin A, Bradford PA: Characterization and sequence analysis of extended-spectrum lactamase-encoding genes from Escherichia coli, Klebsiella pneumoniae, and Proteus mirabilis isolates collected during Tigecycline Phase 3 clinical trials. Antimicrob Agents Chemother 2008, 53(2):465-475.

24. Bali EB, Acik L, Sultan N: Phenotypic and molecular characterization of SHV, TEM, CTX-M and extended-spectrum beta-lactamase produced by Escherichia coli, Acinobacter baumannii and Klebsiella isolates in a Turkish hospital. Afr J Microbiol Res 2010, 4(8):650-654.

25. Hasim RB, Husin S, Rahman MM: Detection of beta-lactamase producing bacterial genes and their clinical features. Pak J Biol Sci 2011, 14(1):41-46.

26. Canton R, Coque TM: The CTX-M beta-lactamase pandemic. Curr Opin Microbiol 2006, 9(5):466-475.

27. Lin CF, Hsu SK, Chen CH, Huang JR, Lo HH: Genotypic detection and molecular epidemiology of extended-spectrum beta-lactamaseproducing Escherichia coli and Klebsiella pneumoniae in a regional hospital in central Taiwan. J Med Microbiol 2010, 59(6):665-671.

28. Eckert C, Gautier V: Dissemination of CTX-M-Type $\beta$-Lactamases among clinical isolates of Enterobacteriaceae in Paris, France. Antimicrob Agents Chemother 2004, 48(4):1249-1255.

29. Tada T, Miyoshi-Akiyama T, Dahal RK, Mishra SK, Ohara H, Shimada K, Kirikae T, Pokhrel BM: Dissemination of multidrug-resistant Klebsiella pneumoniae clinical isolates with various combinations of carbapenemases (NDM-1 and OXA-72) and 16S rRNA methylases (ArmA, RmtC and RmtF) in Nepal. Int J Antimicrob Agents 2013, 42(4):372-374.

doi:10.1186/1756-0500-7-694

Cite this article as: Pokhrel et al: Co-existence of beta-lactamases in clinical isolates of Escherichia coli from Kathmandu, Nepal. BMC Research Notes 2014 7:694

\section{Submit your next manuscript to BioMed Central and take full advantage of:}

- Convenient online submission

- Thorough peer review

- No space constraints or color figure charges

- Immediate publication on acceptance

- Inclusion in PubMed, CAS, Scopus and Google Scholar

- Research which is freely available for redistribution
C Biomed Central 